\title{
Studi Kasus Asuhan Keperawatan Psikososial Dengan Masalah Kecemasan Pada Penderita Hipertensi
}

\section{Roy Ronni Siregar}

\author{
royronnisiregar@gmail.com
}

\section{BAB 1 \\ PENDAHULUAN}

\subsection{Latar Belakang}

Pembangunan kesehatan bertujuan untuk meningkatkan derajat kesehatan masyarakat dalam rangka peningkatan kualitas hidup, kecerdasan dan kesejahteraan masyarakat (Rahmawati dan Ningsih 2016). Hipertensi merupakan penyakit yang muncul karena ketegangan jiwa terutama disaat perasaan marah dan frustasi, dan dapat terjadi akibat konsumsi garam atau natrium, merokok, dan kelebihan berat badan (Savitri 2021). Menurut Word Health Organization (WHO) Hipertensi merupakan penyakit tidak menular yang menjadi salah satu penyebab kematian premature dunia. WHO mengestimasikan prevalensi hipertensi secara global sebesar $22 \%$ dari total penduduk dunia dari sejumlah penderita tersebut kurang dari seperlima yang melakukan upaya pengecualian terhadap tekanan darah yang dimiliki wilayah Afrika memiliki prevalensi hipertensi tertinggi sebesar $27 \%$ mediterania Timur $26 \%$ asia tenggara berada di posisi tertinggi ke-3 dengan prevalensi sebesar $25 \%$ terhadap total penduduk. WHO juga memperkirakan 1 banding 5 perempuan di seluruh dunia memiliki hipertensi jumlah ini lebih besar terdapat di kelompok laki-laki yaitu 1 banding 4 (Kemenkes RI 2019).

Hipertensi menjadi ancaman kesehatan masyarakat karena potensinya yang mampu mengakibatkan kondisi komplikasi seperti stroke, penyakit jantung koroner, dan gagal ginjal. Penegakkan diagnosa dapat dilakukan melalui pengukuran tekanan darah oleh tenaga kesehatan atau kader kesehatan yang telah dilatih dan dinyatakan layak oleh tenaga kesehatan untuk melakukan pengukuran. Hipertensi ditandai dengan hasil pengukuran tekanan darah yang menunjukkan tekanan sistolik sebesar > 140 mmhg atau dan tekanan 
diastolik sebesar > 90 mmhg. Pengukuran tekanan darah dilakukan sesuai dengan standar British Society of Hypertension mengunakan alat sphygmomanometer air raksa, digital atau anaeroid yang telah ditera (Kemenkes RI 2019).

Badan Kesehatan Dunia (WHO) menyatakan bahwa hipertensi merupakan penyebab nomor satu kematian di dunia data Joint National Committee on Prevention, Detection, Evaluation and treatment on High Blood Presure VII yang menyatakan hampir 1 milyar penduduk dunia mengindap hipertensi (Prasetyanigrum 2014). sementara itu, hasil Riset Kesehatan Dasar (Rikesdas) tahun 2018 menunjukkan bahwa provinsi Kalimantan selatan memiliki prevalensi tertinggi sebesar 44,13\% diikuti oleh jawa barat sebesar 39,3\%, Kalimantan timur sebesar 39,3\%, dan Sumatra Utara sebesar 29,19\% sementara provinsi yang memiliki prevalensi yang terendah sebesar 24,65\% dan Sumatra barat sebesar 25,16\% (Kemenkes RI 2019). sementara data dari Laporan Riset Kesehatan Dasar Provinsi Sumatera Utara Tahun 2018, Tapanuli Utara sebesar 41,02, Humbang Hasundutan sebesar 37,69 Mandailing Natal sebesar 25,82\% Tapanuli Selatan sebesar 26,85, dan Medan 25,21\% (Balitbangkes Depkes RI 2018).

Hal ini akan membuat seseorang yang terkena hipertensi akan mengalami gangguan psikis seperti ansietas dan atau depresi. Gangguan psikis seperti ansietas di samping menimbulkan gangguan fungsional jantung juga sebagai salah satu faktor risiko terjadinya penyakit jantung kororner. Selain itu, ansietas dapat memperlambat penyembuhan, meningkatkan komplikasi, dan mortalitas penderita hipertensi (Marta 2013). Ansietas (Kecemasan) merupakan perasaan takut yang tidak jelas penyebabnya dan tidak didukung oleh situasi yang ada. Kecemasan dapat dirasakan oleh setiap orang jika mengalami tekanan dan perasaan mendalam yang menyebabkan masalah Psikiatrik (Marbun, Pardede, dan Perkas 2019). Ansietas merupakan suatu respons emosonal sebagai antisipasi terhadap bahaya, Respon individu terhadap ansietas mempunyai rentang antara adaptif sampai maladaptif. Respon adaftif identik dengan reaksi yang bersifat destruktif. Reaksi yang bersifat kontruktif menunjukkan sikap optimis dan berusaha memahami terhadap perubahan perubahan yang terjadi baik perubahan fisik maupun efektif (Stuart, Keliat dan Pasaribu 2016). 
Apabila respon maladaptif yang muncul pada individu tersebut akan berisiko mengalami gangguan jiwa. Gangguan jiwa adalah salah satu penyebab terhambatnya usaha pengembangan perekonomian di Indonesia karena menurunnya produktifitas dan bertambahnya pengeluaran biaya keluarga atau pemerintah untuk melakukan rehabilitasi Berdasarkan pernyataan tersebut, perlu adanya pelayanan penanggulangan atau pencegahan masalah kesehatan jiwa. Upaya tersebut bisa pelayanan kesehatan jiwa dimasyarakat seperti promotif, preventif, dan rehabilitatif (Hartanto, Hendrawati dan Sugiyorini, 2021).

Survey awal yang dilakukan Kec. Medan Helvetia, Kelurahan Dwi Kora Jalan Budilur gg. Rukun no 78 A maka ditemukan pasien yang mengalami hipertensi diakibatkan hipertensi dengan inisial Tn.S dengan kecemasan.

\subsection{Rumusan Masalah}

Berdasarkan uraian latar belakang maka penulis membuat rumusan masalah sebagai berikut: Asuhan Keperatan psikososial jiwa pada Tn.S dengan Masalah Kecemasan di wilayah Gg. Rukun No 78A Kec. Medan Helvetia.

\subsection{Tujuan}

\subsubsection{Tujuan Umum}

Untuk memberikan asuhan keperawatan Psikososial Jiwa Pada Tn.S Dengan Masalah Kecemasan.

\subsubsection{Tujuan Khusus}

1. Mahasiswa mampu melakukan pengkajian pada Tn.S dengan masalah kecemasan.

2. Mahasiswa mampu menegakkan diagnose pada Tn.S dengan masalah kecemasan.

3. Mahasiswa mampu membuat intervensi pada Tn.S dengan masalah kecemasan

4. Mahasiswa mampu melakukan Implementasi pada $\operatorname{TnS}$ dengan masalah kecemasan. 
5. Mahasiswa mampu melakukan Evaluasi pada Tn.S dengan masalah kecemasan

BAB 2

TINJAUAN TREORITIS 


\subsection{Konsep Hipertensi}

\subsubsection{Defenisi Hipertensi}

Hipertensi adalah suatu keadaan ketika tekanan darah di pembuluh darah meningkat secara kronis. Hal tersebut dapat terjadi karena jantung bekerja lebih keras memompa darah untuk memenuhi kebutuhan oksigen dan nutrisi tubuh. Jika dibiarkan, penyakit ini dapat mengganggu fungsi organ-organ lain, terutama organ-organ vital seperti jantung dan ginjal. Didefinisikan sebagai hipertensi jika pernah didiagnosis menderita hipertensi/penyakit tekanan darah tinggi oleh tenaga kesehatan (dokter/ perawat/ bidan) atau belum pernah didiagnosis menderita hipertensi tetapi saat diwawancara sedang minum obat medis untuk tekanan darah tinggi (minum obat sendiri). Kriteria hipertensi yang digunakan pada penetapan kasus merujuk pada kriteria diagnosis JNC VII 2003, yaitu hasil pengukuran tekanan darah sistolik $\geq 140 \mathrm{mmHg}$ atau tekanan darah diastolik $\geq 90 \mathrm{mmHg}$ (Kemenkes 2013).

Hipertensi merupakan suatu dimana keadaan tekanan darah naik yaitu tekanan darah sistolik $\geq 140 \mathrm{mmHg}$ dan tekanan darah diastolik $\geq 90 \mathrm{mmHg}$ karena gangguan dari pembuluh darah yang mengakibatkan suplai oksigen dan nutrisi yang dibawa oleh darah terhambat sampai kejaringan tubuh yang membutuhkannya (Hastuti 2019).

Jadi dapat disimpukan hipertensi merupakan apabila keadaan individu dimana terjadi peningkatan tekanan darah persisten dengan tekanan darah sistolik $\geq 140$ $\mathrm{mmHg}$ dan tekanan diastolik $\geq 90 \mathrm{mmHg}$ hal ini akan mengakibatkan suplai oksigen dan nutrisi yang dibawa oleh darah terhambat sampai jaringan yang membutuhkannya.

\subsubsection{Klasifikasi hipertensi}


Menurut Join National Comitten on Detection Evolution and Treatment of High Blood Pressure VIII dalam (Hastuti 2019) mengklasifikasikan tekanan darah pada orang dewasa berusia 18 tahun atau ke atas sebagai berikut :

Tabel 1 Klasifikasi Hipertensi

\begin{tabular}{lcc}
\hline Klasifikasi & \multicolumn{2}{c}{ Tekanan Darah } \\
\cline { 2 - 3 } & Sistolik (mmHg) & Diastolik (mmHg) \\
\hline Normal & $<120$ & $<80$ \\
\hline Prehipertensi & $120-139$ & $80-89$ \\
\hline Hipertensi stadium 1 & $140-159$ & $90-99$ \\
\hline Hipertensi stadium 2 & $\geq 160$ & $\geq 100$ \\
\hline
\end{tabular}

(sumber: James, Et al, 2014)

2.1.3 Penyebab hipertensi

Penyebab hipertensi terbagi atas 2 yaitu Essensial \& Sekunder (Hastuti 2019). Penyebab Hipertensi Essensial.

a) Herediter atau factor genetic

b) Lingkungan termasuk asupan garam, Obesitas, pekerjaan, kurang olah raga, asupan alkohol, stress psikososial, jenis kelamin dan usia.

c) Sisten renin, angiotensia, dan aldosteron.

d) Efek membrane sel dalam eskresi Na, yaitu penurunan tekanan Na dari dalam sel yang disebabkan oleh kelainan pada sistem $\mathrm{Na}+\mathrm{K}+\mathrm{ATPase}$ dan $\mathrm{Na}+\mathrm{H}+$ excharger.

e) Resistensi insulin atau hiperinsulinemia mengakibatkan resistensi natrium ginjal, meningkatkan saraf simpatis, meningkatkan tekanan arteri polos dan hipertrofi otot polos.

2. Penyebab Hipertensi sekunder
a) Penggunaan estrogen.
b) Penyakit ginjal.
c) Hipertensi vaskuler renal.
d) Hiperaldosteronisme primer.
e) Sindrome chusing. 
f) Feokromositoma

g) Koarktasio aorta.

h) Kehamilan.

\subsubsection{Faktor risiko hipertensi}

Faktor risiko hipertensi dibagi menjadi 2 kelompok yaitu faktor yang tidak dapat diubah dan faktor yang dapat diubah. Faktor risiko yang tidak dapat diubah antara lain umur, jenis kelamin, dan genetik. Faktor risiko yang dapat diubah antaralain kebiasaan merokok, konsumsi serat, stres, aktivitas fisik, konsumsi garam, kegemukan, kebiasaan konsumsi alkohol dan dislipidemia ( Kementerian Kesehatan RI 2013).

2.1.5 Tanda dan gejala hipertensi

Kenaikan tekanan darah kadang merupakan satu-satunya gejala. Kadang gejala hipertensi primer berjalan tanpa gejala baru timbul gejala setelah terjadinya komplikasi pada organ target seperti pada ginjal,mata otak dan jantung, gejala hipertensi bervariasi pada masing-masing individu dan hampir sama dengan penyakit lain seperti : Sakit kepala, Jantung berdebar-debar, sulit bernafas setelah bekerja keras atau mengangkat beban berat, mudah lelah, penglihatan kabur, Wajah memerah, Hidung berdarah, Sering buang air kecil, terutama dimalam hari, telinga berdering, dunia terasa berputar (Hastuti, A. P, 2020).

2.1.6 Mekanisme terjadinya hipertensi

Mekanisme yang mengontrol kontriksi dan relaksasi pembuluh darah dimulaidari jaras saraf simpatis yang berada dipusat vasomotor medula spinalis. Jaras saraf simpatis dari medula spinalis berlanjut ke korda spinalis dan keluar dari kolumna medula spinalis menuju ganglia simpatis di toraks dan abdomen. Rangsangan pusat vasomotor disampaikan ke ganglia simpatis melalui impuls yang kemudian neuron preganglion mengeluarkan asetilkolin yang akan merangsang serabut saraf pasca ganglion ke pembuluh darah. Pelepasan norepinefrin akan menyebabkan terjadinya kontriksi pembuluh darah.

Saraf simpatis sebagai perangsang pembuluh darah sebagai respon terhadap emosi, juga mengakibatkan tambahan pada aktivitas vasokonstriksi. Medula 
adrenal mengeluarkan epinefrin, kortisol, dan steroid lainnya yang menyebabkan vasokonstriks. Vasokonstriksi merangsang pengeluaran renin akibat penurunan aliran darah ke ginjal. Sekresi renin akan merangsang pelepasan angiotensin I yang kemudian diubah menjadi angitensin II dan merangsang korteks adrenal mengeluarkan aldosteron. Hormon aldosteron akan menyebabkan retensi natrium dan air oleh tubulus ginjal sehingga meningkatkan volume intravaskular. Semua mekanisme tersebut mencetuskan terjadinya peningkatan tekanan darah.

\subsubsection{Penatalaksanaan hipertensi}

Penatalaksanaan hipertensi dibagi menjadi dua yaitu penetalaksanaan denganterapi farmakologis dan non farmakologis.

1. Terapi farmakologis

Berbagai penelitian klinis membuktikan bahwa, obat anti hipertensi yang diberikan tepat waktu dapat menurunkan kejadian stroke hingga 35-40\%, infark miokard 20-25\%, dan gagal jantung lebih dari $50 \%$. Obat-obatan yang diberikan untuk penderita hipertensi meliputi diuretik, angiotensinconverting enzyme (ACE), Beta-blocker, calcium channel blocker (CCB), dll. Diuretik merupakan pengobatan hipertensi yang pertama bagi kebanyakan orang dengan hipertensi (Kementerian Kesehatan RI, 2013)

2. Terapi non farmakologis

Makan gizi seimbang

3. Pengelolaan diet yang sesuai terbukti dapat menurunkan tekanan darah pada penderita hipertensi. Manajemen diet bagi penderita hipertensi yaitu membatasi gula, garam, cukup buah, sayuran, makanan rendah lemak, usahakan makan ikan berminyak seperti tuna, makarel dan salmon Kemenkes RI 2019.

4. Mengurangi berat badan

Hipertensi erat hubungannya dengan kelebihan berat badan. Mengurangi berat badan dapat menurunkan tekanan darah karena mengurangi kerja jantung dan volume sekuncup (Aspiani, 2015). Penderita hipertensi yang mengalami kelebihan berat badan (obesitas) dianjurkan untuk menurunkan 
berat badan hingga mencapai IMT normal 18,5 - 22,9 kg/m², lingkar pinggang $<90 \mathrm{~cm}$ untuk laki-laki dan $<80 \mathrm{~cm}$ untuk perempuan.

5. Olahraga yang teratur.

Olahraga teratur seperti berjalan, lari, berenang dan bersepeda bermanfaat untuk menurunkan tekanan darah dan memperbaiki kinerja jantung (Aspiani, 2015). Senam aerobic atau jalan cepat selama 30-45 menit lima kali perminggu dapat menurunkan tekanan darah baik sistole maupun diastole. Selain itu, berbagai cara relaksasi seperti meditasi dan yoga merupakan alternatif bagi penderita hipertensi tanpa obat.

6. Berhenti Merokok

Berhenti merokok dapat mengurangi efek jangka panjang hipertensi karenan asap rokok yang mengandung zat-zat kimia beracun seperti nikotin dan karbon monoksida yang dihisap melalui rokok dapat menurunkan aliran dara ke bebagai organ dan meningkatkan kerja jantung.

7. Mengurangi konsumsi alkohol

Mengurangi konsumsi alkohol dapat menurunan tekanan darah sistolik.Sehingga penderita hipertensi diupayakan untuk menghindari konsumsi alkohol.

8. Mengurangi stress

Stres dapat memicu penurunan aliran darah ke jantung dan meningkatkan kebutuhan oksigen ke berbagai organ sehingga meningkatkan kinerja jantung, olehkarena itu dengan mengurangi stres seseorang dapat mengontrol tekanan darahnya.

\subsubsection{Komplikasi hipertensi}

Tekanan darah yang tidak terkontrol dan tidak segera diatasi dalam jangka panjang akan mengganggu pembuluh darah arteri dalam mensuplai darah ke organ- organ diantaranya jantung, otak, ginjal dan mata. Hipertensi yang tidak terkontrol berakibat komplikasi pada jantung meliputi infark jantung dan pembesaran ventrikel kiri dengan atau tanpa payah jantung. Hematuria (urine yang disertai darah) dan oliguria (kencing sedikit) merupakan komplikasi 
hipertensi pada ginjal. Komplikasi hipertensi juga dapat terjadi pada mata berupa retinopati hipertensi. Stroke dan euchephalitis merupakan penyakit yang terjadi pada organ otak sebagaiakibat hipertensi yang tidak ditangani dalam waktu lama

\subsection{Konsep Ansietas}

\subsubsection{Defenisi Ansietas}

Ansietas adalah perasaan was-was, Khawatir, takut yang tidak jelas atau tidak nyaman seakan-akan terjadi sesuatu yang mengancam. Ansietas adalah perasaan yang tidak nyaman atau ketakutan yang tidak terlalu jelas disertai respon otonom, perasaan takut yang disebabkan oleh antisipasi terhadap bahaya hal ini merupakan isyaratkewaspadaan yang memperingati individu akan adanya bahaya dan memampukan individu untuk bertindak menghadapi ancaman (Keliat, A, B 2019).

Ansietas di definisikan sebagai gangguan kejiwaan yang paling umum dengan gejala kekhawatiran yang berlebihan, hiperaousal, serta kekuatan yang kontra produktif dan melemahkan meskipun kurang terlihat seperti skizofrenia, depresi atau gangguan biopolar, ansietas bisa sama-sama melumpuhkan (Azzahra, F., Oktarlina, R. Z., \& Hutasoit, H. B. K. 2020).

Penulis menyebutkan bahwa ansietas Ansietas adalah perasaan tidak senang yang khas yang diakibatkan oleh dugaan akan bahaya atau frustrasi yang mengancam yang akan membahayakan rasa aman, keseimbangan, atau kehidupan seseorang individu atau kelompok biososialnya.

\subsubsection{Etiology}

Meski penyebab ansietas belum sepenuhnya diketahui, namun gangguan keseimbangan neurotransmitter dalam otak dapat menimbulkan ansietas pada diri seseorang. Faktor genetik juga merupakan faktor yang dapat juga menimbulkan gangguan ini, ansietas terjadi ketika seseorang mengalami kesulitan menghadapi situa si, masalah dan tujuan hidup Setiap individu menghadapi stress dengan cara berbeda-beda, seseorang dapat tumbuh dalam situasi yang dapa menimbulkan 
stress berat pada orang lain adapun faktor-faktornya yang mempengaruhi ansietas adalah :

\section{Faktor predisposisi}

Berbagai teori yang dikembangkan untuk menjelaskan penyebab ansietas adalah:

a) Teori psikionalitik

Ansietas merupakan konflik emosional antara dua elemen yaitu ide, ego dan super ego. Ide melambangkan dorongan insting, ego digambarkan sebagai mediator antara ide dan super ego mencerminkan hati nurani seseorang dan dikendalikan oleh norma-norma budaya seseorang, ansietas berfungsi untuk memperingatkan ego tenang suatu budaya yang perlu segera diatasi.

b) Teori interpersonal

Ansietas terjadi dari ketakutan akan penolakan interpersonal berhubungan juga dengan trauma masa perkembangan seperti kehilangan, perpisahan. Individu dengan harga diri rendah biasanya sangat mengalami ansietas berat.

c) Teori perilaku

Ansietas merupakan produk frustasi yaitu segala sesuatu yang yang menggangu kemampuan seseorang untuk mencapai tujuan yang diharapkan.

d) Kajian biologis

Kajian biologis menunjukan bahwa otak mengandung reseptor khusus untuk benzodiazepin, obat-obatan yang meningkatan neuroregulator yang berperan penting dalam mekanisme biologis yang berhubungan dengan ansietas (Stuart, Keliat, dan Pasaribu 2016).

e) Faktor presipitasi

Bersumber dari eksternal dan internal seperti :

1. Ancaman terhadap integritas fisik meliputi ketidakmampuan fisiologis atau menurunnya kemampuan melaksanakan fungsi kehidpan sehari-hari (Stuart, Keliat, dan Pasaribu 2016). 
2. Ancaman terhadap sistem diri dapat membahayakan identitas harga diri dan integritas fungsi sosial (Stuart, Keliat, dan Pasaribu 2016).

f) Perilaku

Ansietas dapat diekspresikan langsung melalui perubahan fisiologis dan perilaku secara tidak langsung timbulnya gejala atau mekanisme koping dalam meningkat sejalan dengan peningkatan ansietas

\subsubsection{Tingkat Ansietas}

1. Ansietas Ringan

Ansietas ringan berhubungan dengan ketengan akan peristiwa kehidupan sehari-hari. Pada tingkat ini laangan persepsi melebar dan individu terdorong untuk belajar yang akan menghasilkan pertumbuhan kreatifitas.

a. Respon fisiologis

1. Sesekali napas pendek

2. Nadi dan tekanan darah naik

3. Gejala ringan pada lambung

4. Muka berkerut dan bibir bergetar

b. Respon kognitif

1. Lapang persepsi melebar

2. Mampu menerima rangsangan yang kompleks

3. Konsentrasi pada maslah

4. Menejlaskan masalah secara efektif

c. Respon perilaku dan emosi

1. Tidak dapat duduk tenang

2. Tremor halus pada tangan

3. Suara kadang-kadang meninggi

2. Ansietas sedang Pada tingkat ini lapangan persepsi terhadap lingkugan menurun. Individu lebih memfokuskan hal-hal penting dan mengenyampingkan hal-hal lain

a. Respon fisiologis 
1. Nadi (ekstra systole) dan tekanan darah naik

2. Mulut kering

3. Anorexia

4. Diare/konstipasi

5. Gelisah

b. Respon kognitif

1. Lapang persepsi menyempit

2. Rangsang luar tidak mampu diterima

3. Berfokus pada apa yang menjadi perhatian

c. Respon perilaku dan emosi

1. Gerakan tersentak-sentak (meremas tangan)

2. Bicara banyak dan lebih cepat

3. Susah tidur

4. Perasaan tidak aman

3. Ansietas berat

Pada ansietas berat lapangan persepsi menjadi sangat sempit, individu cenderung memikirkan hal yang kecil saja dan mengabaikan hal lain,individu tidak mampu lagi berpikir realistis dan membutuhkan pengarahan untuk memusatkan perhatian pada area lain (Pardede, J. A., Sitepu, S. F. A., \& Saragih, M. (2018) :

a. Respon fisiologi

1. Sering nafas pendek Nadi dan tekanan darah naik

2. Berkeringat dan sakit kepala

3. Penglihatan kabur

4. Ketegangan

b. Respon kognif

1. Lapang persepsi sangat sempit

2. Tidak mampu menyelesaikan masalah

c. Respon perilaku dan emosi

d. Perasaan ancam meningkat 
1. verbialisasi cepat

\section{e. Blocking}

\subsubsection{Mekanisme Koping}

Ketika pasien mengalami ansietas, individu menggunakan bermacam-macam mekanisme koping untuk mencoba mengatasinya. Dalam bentuk ringan ansietas bentuk ringan ansietas dapat di atasi dengan menangis, tertawa, tidur, olahraga atau merokok Pardede, J. A., Simanjuntak, G. V., \& Laia, R. (2020). Bila terjadi ansietas berat sampai panik akan terjadi ketidakmampuan mengatasi ansietas secara konstruktif merupakan penyebab utama perilaku yang patologis, individu akan menggunakan energy yang lebih besar untuk dapat mengatasi ancaman tersebut.

Mekanisme koping untuk mengatasi ansietas adalah :

a. Reaksi yang berorientasi pada tugas (task oriented reaction) Merupakan pemecahan masalah secara sadar yang digunakan untuk menanggulangi ancaman stressor yang ada secara realistis yaitu:

1. Perilaku menyerang (Agresif) Biasanya digunakan individu untuk mengatasi rintangan agar memenuhi kebutuhan.

2. Perilaku menarik diri Digunakan untuk menghilangkan sumber ancaman baik secara fisik maupun psikologis.

3. Perilaku kompromi Digunakan untuk merubah tujuan yang akan dilakukan atau mengorbankan kebutuhan personal untuk mencapai tujuan.

b. Mekanisme pertahanan ego (Ego oriented reaction) Mekanisme ini membantu mengatasi ansietas ringan dan sedang yang digunakan untuk melindungi diri dan dilakukan secara sadar untuk mempertahankan keseimbangan. Mekanisme pertahanan ego:

1. Disosiasi adalah pemisahan dari proses mental atau perilaku dari kesadaran atau identitasnya. 
2. Identifikasi (identification) adalah proses dimana seseorang untuk menjadi yang ia kagumi berupaya dengan mengambil/meniru pikiranpikiran, perilaku dan selera orang tersebut.

3. Intelektualisasi (intellectualization) adalah penggunaan logika dan alasan yang berlebihan untuk menghindari pengalaman yang mengganggu perasaannya.

4. Introjeksin (introjection) adalah suatu jenis identifikasi yang dimana seseorang mengambil dan melebur nilai-nilai dan kualitas seseorang atau suatu kelompok kedalam struktur egonya sendiri, berupa hati nurani, contohnya rasa benci atau kecewa terhadap kematian orang yang dicintai, dialihkan dengan cara menyalahkan diri sendiri.

5. Kompensasi adalah proses dimana seseorang memperbaiki penurunan citra diri dengan secara tegas menonjolkan keistimewaan/kelebihan yang dimilikinya. Penyangkalan (Denial) adalah menyatakan ketidaksetujuan terhadap realitas dengan mengingkari realitas tersebut. Mekanisme pertahanan ini adalah penting, sederhana, primitif.

6. Pemindahan (displacement) adalah pengalihan emosi yang semula ditujukan pada seseorang/benda kepada orang lain/benda lain yang biasanya netral atau kurang mengancam dirinya.

7. Isolasi adalah pemisahan unsur emosional dari suatu pikiran yang menggangu dapat bersifat sementara atau berjangka lama.

8. Proyeksi adalah pengalihan buah pikiran atau impuls pada diri sendiri kepada orang lain terutama keinginan, perasaan emosional dan motivasi yang tidak dapat ditoleransi.

9. Rasionalisasi adalah mengemukakan penjelasan yang tampak logis dan dapat diterima masyarakat untuk membenarkan perasaan perilaku dan motif yang tidak dapat diterima.

10. Reaksi formasi adalah pengembangan sikap dan pola perilaku yang ia sadari yang bertentangan dengan apa yang sebenarnya ia rasakan atau ingin dilakukan. 
11. Regresi adalah kemunduran akibat stress terhadap perilaku dan merupakan ciri khas dari suatu taraf perkembangan yang lebih dini.

12. Represi adalah pengenyampingkan secara tidak sadar tentang-tentang pikiran, ingatan yang menyakitkan atau bertentangan ,dari kesadaran seseorang merupakan pertahanan ego yang primer yang cenderung diperkuat oleh mekanisme lain. 


\section{BAB 3}

\section{TINJAUAN KASUS}

\subsection{PENGKAJIAN KEPERAWATAN}

\begin{tabular}{|l|l|}
\hline Nama : Tn .S & Kondisi saat MRS: \\
Usia : 70 tahun & Kondisi saat ini : \\
Tahun no reg : - & Tn. S mengeluh merasa cemas \\
Ruangan : - & dengan kondisinya saat ini yang \\
Tgl masuk rs: - & sering mengalami kekambuhan \\
Tgl pengkajian : 4 Oktober 2021 & penyakitnya sehingga membuta \\
Alamat: Gg. Rukun No 78A & Tn. S kesulitan untuk beraktivitas, \\
& Tn.S juga mengatakan pandangan- \\
& nya rabun dan lemas. \\
\hline
\end{tabular}




\subsubsection{FAKTOR PREDIPOSISI DAN FAKTOR PREDISIPITASI}

\begin{tabular}{|c|c|c|c|c|}
\hline \multirow[t]{2}{*}{ Faktor Prediposisi } & \multicolumn{3}{|l|}{ Faktor predisipitasi } & \multirow[t]{2}{*}{ Stresor } \\
\hline & Nature & Origin & Number \& Timing & \\
\hline $\begin{array}{l}\text { Biologis : } \\
\text { 1.Hipertensi } \\
\text { 2.Tn. S menderita Hipertensi Sejak } 5 \text { tahun } \\
\text { yang lalu } \\
\text { 3.Tn.S Sering mengonsumsi makanan yang } \\
\text { asin }\end{array}$ & $\begin{array}{l}\checkmark \text { Badan lemas pandangan } \\
\text { kabur, tekanan darah } \\
\text { tinggi. }\end{array}$ & Internal & $\begin{array}{ll}\text { Saat dilakukan } \\
\text { pengkajian }\end{array}$ & Hipertensi \\
\hline $\begin{array}{l}\text { Psikologis : } \\
\text { 1. Tn.S memiliki kepribadian yang terbuka } \\
\text { setiap ada masalah akan dibicarakan } \\
\text { dengan istri } \\
\text { 2. Tn.S merasa pening dan nafas pendek }\end{array}$ & $\begin{array}{l}\checkmark \text { Gelisah, jantungan } \\
\text { berdebar, gemetaran. } \\
\checkmark \text { Kepikiran dengan } \\
\text { penyakitnya karena umur } \\
\text { semakin tua. }\end{array}$ & Internal & $\begin{array}{ll}\text { Sejak } & \text { terkena } \\
\text { Hipertensi } & \end{array}$ & $\begin{array}{l}\text { Ansietas, Panik, } \\
\text { Khawatir. }\end{array}$ \\
\hline $\begin{array}{l}\text { Sosialcultural : } \\
\text { 1. Tn.S Seorang laki-laki umur } 70 \text { tahun } \\
\text { 2. Tn.S menikah dan memiliki } 5 \text { orang anak } \\
\text { 3. Tn.S merupakan skepala keluarga. } \\
\text { 4. Sebelumnya Tn.S aktif terlibat dalam } \\
\text { kegiatan lingkungan tempat tinggal }\end{array}$ & & & & \\
\hline
\end{tabular}




\begin{tabular}{|l|l|l|l|}
\hline seperti pengkajian. & & \\
5. Tn.S merupakan orang jawa dan menurut \\
Tn.S tidak ada kebiasaan yang \\
bertentangan dengan kesehatan. \\
6. Tn.S beragama islam dan taat \\
menjalankan ibadah.
\end{tabular}

\subsubsection{PENILAIAN TERHADAP STRESOR}

\begin{tabular}{|c|c|c|c|c|c|c|}
\hline STRESSOR & KOGNITIF & AFEKTIF & FISIKOLOGIS & PERILAKU & SOSIAL & $\begin{array}{l}\text { DIAGNOSIS } \\
\text { KEPERAWATAN }\end{array}$ \\
\hline $\begin{array}{l}\text { BIOLOGIS } \\
\text { Hipertensi }\end{array}$ & $\begin{array}{l}\text { - Menurut } \\
\text { Tn.S } \\
\text { penyakit } \\
\text { hipertensi } \\
\text { diakibatka } \\
\text { n karena } \\
\text { mengkons } \\
\text { msi } \\
\text { makanan } \\
\text { asin } \\
\text { - Mengangg } \\
\text { ap }\end{array}$ & $\begin{array}{l}\text { Tn.S merasa } \\
\text { takut } \\
\text { karena } \\
\text { umurnya } \\
\text { semakin } \\
\text { menua } \\
\text { disertai }\end{array}$ & $\begin{array}{l}\text { - } \text { TD naik } \\
\text { - Banyak } \\
\text { Berkeringat } \\
\text { - Rasa sakit } \\
\text { kepala } \\
\text { - Sulit tidur } \\
\text { - penglihatan } \\
\text { kabur } \\
\text { - Tn.S tampak } \\
\text { - } \text { lemas } \\
\text { - Pemeriksaan }\end{array}$ & $\begin{array}{ll}\text { - } & \text { Tn.S } \\
\text { merasa } \\
\text { perasaannya } \\
\text { tidak aman } \\
\text { - } \text { Tn.S } \\
\text { tampak } \\
\text { gelisah }\end{array}$ & $\begin{array}{l}\text { Tn. S ketempat } \\
\text { pelayanan kesehatan } \\
\text { dan menggunakan } \\
\text { fasilitas kesehatan } \\
\text { untuk mendapatkan } \\
\text { perawatan. }\end{array}$ & Ansietas \\
\hline
\end{tabular}




\begin{tabular}{|c|c|c|c|c|c|c|}
\hline & $\begin{array}{l}\text { penyakit } \\
\text { yang } \\
\text { diderita } \\
\text { berbahaya }\end{array}$ & $\begin{array}{l}\text { dengan } \\
\text { kondisi } \\
\text { penyakitnya }\end{array}$ & $\begin{array}{l}\text { TTV } \\
\text { TD: } 170 / 100 \\
\text { mmhg } \\
\mathrm{N}: 90 \mathrm{x} / \text { menit } \\
\mathrm{P}: 24 \mathrm{x} / \text { menit } \\
\text { S: } 37.5^{\circ} \mathrm{C}\end{array}$ & & & \\
\hline $\begin{array}{l}\text { Psikologis : } \\
\text { - Sedih, Cemas, } \\
\text { dengan kondisi } \\
\text { penyakit } \\
\text { pengobatan } \\
\text { serta } \\
\text { perawatannya } \\
\text { - Pasien kurang } \\
\text { percaya diri } \\
\text { dengan } \\
\text { perubahan } \\
\text { fisiknya yang } \\
\text { dialaminya } \\
\text { badan sudah } \\
\text { semakin tua, } \\
\text { tubuh semakin } \\
\text { tua dan lemah. }\end{array}$ & $\begin{array}{l}\text { Tn.S tahu } \\
\text { bahwa } \\
\text { badannya } \\
\text { menjadi lemah } \\
\text { gemetaran dan } \\
\text { jantungan } \\
\text { berdebar } \\
\text { kencang } \\
\text { merupakan } \\
\text { dampak dari } \\
\text { penyakit yang } \\
\text { diderita }\end{array}$ & $\begin{array}{l}\text { - Merasa } \\
\text { takut } \\
\text { dengan } \\
\text { penyakitn } \\
\text { ya yang } \\
\text { akan } \\
\text { membuat } \\
\text { dia } \\
\text { semakin } \\
\text { lemah. } \\
\text { - Kurang } \\
\text { percaya } \\
\text { diri }\end{array}$ & 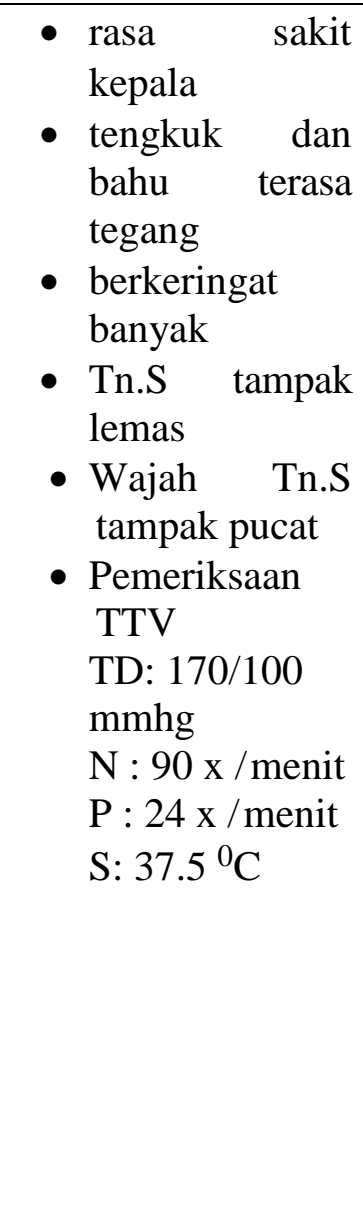 & $\begin{array}{l}\text { - } \text { Tampak } \\
\text { cemas dan } \\
\text { tidak } \\
\text { tenang } \\
\text { - Tn.S } \\
\text { tampak } \\
\text { gelisah } \\
\text { - Tn.S } \\
\text { tampak } \\
\text { sedih saat } \\
\text { bercerita }\end{array}$ & $\begin{array}{l}\text { - } \begin{array}{l}\text { Hubungan } \\
\text { dengan istri baik } \\
\text { baik }\end{array} \\
\text { - } \text { Tn.S tetap mengikuti } \\
\text { program pengobatan } \\
\text { yang diberikan } \\
\text { kepadanya }\end{array}$ & $\begin{array}{l}\text { - Ansietas } \\
\text { - Gangguan citra } \\
\text { tubuh }\end{array}$ \\
\hline Sosial Budaya & - Tn.S & 1) Merasa & - Sakit Kepala & - Kontak & - Hubungan & Penampilan peran \\
\hline
\end{tabular}




\begin{tabular}{|c|c|c|c|c|c|c|}
\hline $\begin{array}{l}\text { - Sering } \\
\text { memikirkan } \\
\text { anak-anaknya } \\
\text { yang jauh dari } \\
\text { rumahnya } \\
\text { - Merasa kasihan } \\
\text { dengan istrinya }\end{array}$ & $\begin{array}{l}\text { merasa } \\
\text { tidak } \\
\text { berdaya } \\
\text { dengan } \\
\text { keadaanny } \\
\text { a sekarang } \\
\text { yang tidak } \\
\text { bisa } \\
\text { bekerja } \\
\text { dan } \\
\text { beraktivita } \\
\text { s lebih } \\
\text { merasa } \\
\text { Kasihan } \\
\text { kepada } \\
\text { Istrinya } \\
\text { yang harus } \\
\text { menjaga } \\
\text { dan } \\
\text { merawatn } \\
\text { ya }\end{array}$ & $\begin{array}{l}\text { khawatir } \\
\text { dan sedih } \\
\text { kepada } \\
\text { Istrinya } \\
\text { yang } \\
\text { merawatnya } \\
\text { karena } \\
\text { Istrinya juga } \\
\text { sudah tua } \\
\text { dan sakit- } \\
\text { sakitan } \\
\text { 2)Merasa } \\
\text { bosan } \\
\text { dengan } \\
\text { keadaan } \\
\text { sekarang } \\
\text { karena } \\
\text { merepotkan } \\
\text { keluarga. }\end{array}$ & $\begin{array}{l}\text { - } \text { Tn.S tampak } \\
\text { kurang tidur. } \\
\text { - } \text { Tengkuk bahu } \\
\text { terasa tegang } \\
\text { - Tn.S tampak } \\
\text { lemas }\end{array}$ & $\begin{array}{l}\text { mata ada } \\
\text { tetapi } \\
\text { tidak } \\
\text { bertahan } \\
\text { lama } \\
\text { - Volume } \\
\text { suara } \\
\text { mengecil } \\
\text { - Tn.S } \\
\text { tampak } \\
\text { gelisah } \\
\text { - Expresi } \\
\text { wajah } \\
\text { klien } \\
\text { tampak } \\
\text { khawatir }\end{array}$ & $\begin{array}{l}\text { dengan istri baik } \\
\text { - Hubunga Tn.S } \\
\text { dengan anak-anak } \\
\text { baik } \\
\text { - Tn.S tetap mengikuti } \\
\text { program pengobatan }\end{array}$ & tidak efektif \\
\hline
\end{tabular}




\subsubsection{SUBER KOPING}

\begin{tabular}{|c|c|c|c|c|c|}
\hline $\begin{array}{l}\text { Dianosa } \\
\text { Keperawatan }\end{array}$ & $\begin{array}{l}\text { Personal } \\
\text { Ability }\end{array}$ & Sosial Upport & Material Assets & Positie Belief & Terapi \\
\hline Ansietas & $\begin{array}{l}\text { Tn.S mampu } \\
\text { mengungkapka } \\
\text { n perasaan } \\
\text { cemas }\end{array}$ & $\begin{array}{l}\text { Tn.S } \\
\text { mendapatkan } \\
\text { dukungan dar } \\
\text { keluarga untuk } \\
\text { kesembuhannya } \\
\text { terutama dari } \\
\text { suaminya }\end{array}$ & 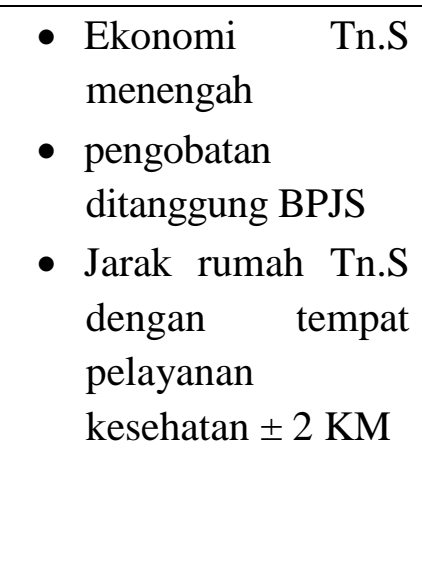 & $\begin{array}{l}\text { - Tn.S percaya bahwa } \\
\text { petugas kesehatan akan } \\
\text { membantunya } \\
\text { - Tn.S berharap cepat } \\
\text { sembuh agar tidak } \\
\text { merepotkan }\end{array}$ & $\begin{array}{l}\text { Terapi Generalisasi : } \\
\text { 1) SP 1-4 Kecemasan } \\
\text { untuk individu } \\
\text { Terapi spesialis: } \\
\text { - Relaksasi progresif: } \\
\text { - Behavior Theraphy } \\
\text { - Psikoedukasi } \\
\text { keluarga }\end{array}$ \\
\hline
\end{tabular}




\begin{tabular}{|c|c|c|c|c|c|}
\hline & $\begin{array}{l}\text { mampu } \\
\text { sebagai } \\
\text { pengganti } \\
\text { akibat } \\
\text { Skondisi } \\
\text { yang } \\
\text { berubah }\end{array}$ & & & & \\
\hline $\begin{array}{l}\text { Gangguan } \\
\text { Citra Tubuh }\end{array}$ & $\begin{array}{l}\text { - Tn.S kurang } \\
\text { percaya diri } \\
\text { dengan } \\
\text { perubahan } \\
\text { fisik yang } \\
\text { dialaminya. }\end{array}$ & $\begin{array}{l}\text { Tn.S mendapat } \\
\text { dukungan dari } \\
\text { keluarga untuk } \\
\text { kesembuhannya } \\
\text { terutama dari } \\
\text { Istrinya }\end{array}$ & $\begin{array}{l}\text { - Sosial ekonomi Tn.S } \\
\text { menengah } \\
\text { - Sarana prasarana } \\
\text { tersedia. } \\
\text { - Jarak dari rumah } \\
\text { Tn.S dengan tempat } \\
\text { pelayanan kesehatan } \\
\text { sekitar } 3 \mathrm{KM}\end{array}$ & $\begin{array}{l}\text { - } \text { Tn.S percaya bahwa } \\
\text { petugas kesehatan akan } \\
\text { membantunya } \\
\text { - Tn.S berharap cepat } \\
\text { sembuh agar tidak } \\
\text { merepotkan } \\
\text { - Tn.S selalu berdoa untuk } \\
\text { kesembuhan penyakitnya } \\
\text { - Tn.S yakin, bila ia } \\
\text { mengikuti petunjuk dan } \\
\text { saran dari petugas } \\
\text { kesehatan maka ia akan } \\
\text { cepat sembuh } \\
\text { - Tn.S yakin suami dan } \\
\text { keluarga mendukung } \\
\text { supaya lekas sembuh }\end{array}$ & $\begin{array}{l}\text { Terapi generalis: } \\
\text { - Gangguan Citra } \\
\text { tubuh } \\
\text { Terapi spesialis: } \\
\text { - Terapi Kognitif }\end{array}$ \\
\hline
\end{tabular}




\subsubsection{MEKANISME KOPING}

\begin{tabular}{|c|c|}
\hline HAL YANG DILAKUKAN & ANALISA \\
\hline $\begin{array}{l}\text { - Tn. S mengatakan bila ada masalah, maka } \\
\text { istrinya akan membicarakan dengan dan } \\
\text { keluarga untuk mencari jalan keluarnya } \\
\text { - Bila sakit Tn. S berobat ke pelayanan } \\
\text { kesehatan } \\
\text { - Tn.S taat menjalankan ibadah sesuai } \\
\text { dengan keyakinannya } \\
\text { - Tn.S selalu berdoa kepada Allah SWT } \\
\text { untuk kesembuhannya }\end{array}$ & $\begin{array}{l}\text { - Konstruktif: } \\
\text { - Tn.S mengatakan bila ada masalah, } \\
\text { maka ia akan membicarakan } \\
\text { dengan istrinya dan keluarga untuk } \\
\text { mencari jalan keluarnya } \\
\text { - Bila sakit Tn.S berobat ke } \\
\text { pelayanan kesehatan } \\
\text { - Tn.S taat menjalankan ibadah } \\
\text { sesuai dengan keyakinannya } \\
\text { Tn.S selalu berdoa kepada Allah } \\
\text { SWT untuk kesembuhannya } \\
\text { mengatakan bila ada masalah, } \\
\text { maka ia akan membicarakan } \\
\text { dengan istrinya dan keluarga untuk } \\
\text { mencari jalan keluarnya } \\
\text { Bila sakit Tn.S berobat ke } \\
\text { pelayanan kesehatan } \\
\text { Tn.S taat menjalankan ibadah } \\
\text { sesuai dengan keyakinannya } \\
\text { Tn.S selalu berdoa kepada Allah } \\
\text { Destruktif untuk kesembuhannya. }\end{array}$ \\
\hline
\end{tabular}




\subsubsection{STATUS MENTAL}

\begin{tabular}{|l|l|}
\hline 1. Penampilan & Bersih, Rapi, Tidak tercium bau, Tn.S tampak gelisah \\
\hline 2. Pembicaraan & Berbicara dengan jelas \\
\hline 3. Aktifitas motoric & Saat di wawancara pasien tampak gelisah \\
\hline 4. Interaksi selama wawancara & Cukup kooperatif \\
\hline 5. Alam perasaan & Tn.S menunjukkan ekspresi takut dan khawatir \\
\hline 6. Afek & Sesuai dengan stimulus yang diberikan \\
\hline 7. Presepsi & Tn.S tidak mengalami ganguan presepsi dan sensori \\
\hline 8. Isi piker & Sebagian sudah sulit diingat karena umur sudah tua \\
\hline 9. Proses piker & Cukup Baik \\
\hline 10. Tingkat kesadaran & Compos mentis (Normal) \\
\hline 11. Daya ingat & Tn.S tidak mengingat beberapa kejadian dalam hidupnya \\
\hline 12. Kemampuan berhitung & Kemampuan berhitung cukup baik \\
\hline 13. Penilaian & $\begin{array}{l}\text { Tn.S belum mampu menyebutkan bagaimana Tn.S lekas } \\
\text { sembuh. }\end{array}$ \\
\hline 14. Daya titik diri & $\begin{array}{l}\text { Tn.S menyadari bahwa saat ini ia sedang sakit, Tn.S hanya } \\
\text { bisa berdoa supaya lekas sembuh agar tidak } \\
\text { merepotkan keluarganya. Tn.S menyadari ia memiliki istri, } \\
\text { anak-anak dan keluarga yang menyanginya } \\
\text { mendukung kesembuhannya }\end{array}$ \\
\hline
\end{tabular}

Kesimpulan : Mental Status Examination (MSE) tidak ada masalah gangguan jiwa, gangguan Tn.A lebih kepada Gangguan Mental Emosional (GME/Psikososial) 


\subsection{DIAGNOSA DAN TERAPI}

\begin{tabular}{|l|l|}
\hline DIAGNOSA KEPERAWATAN DAN & DIAGNOSA MEDIS \\
TERAPI KEPERAWATAN & Hipertensi \\
\hline Ansietas & \\
Sp1: mendiskusikan & \\
penyebab,terjadinya prosesterjadi, & \\
tanda gejala,akibat & \\
Sp2 :melatih teknik releksasi fisik & \\
Sp3:melatih mengatasi ansietas & \\
dengan distraksi dan hipnotis lima & \\
jari & \\
Terapi Spesialis: TS, PMR, Logo & \\
ACT & \\
Penampilan peran tidak efektif \\
Terapi perilaku \\
Gangguan Citra tubuh \\
Kaji tanda dan gejala gangguan \\
citra tubuh dan kemampuan klien \\
mengatasi. \\
Jelaskan tanda dan gejala \\
penyebab akibat gangguan citra \\
tubuh. \\
Memotivasi klien untuk merawat \\
dan meningkatkan citra tubuh \\
sesuai jadwal dan beri pujian.
\end{tabular}




\subsection{IMPLEMENTASI TINDAKAN KEPERAWATAN DAN EVALUASI}

\begin{tabular}{|c|c|}
\hline $\begin{array}{l}\text { IMPLEMENTASI TINDAKAN } \\
\text { KPERAWATAN }\end{array}$ & EVALUASI \\
\hline $\begin{array}{l}\text { Tanggal : } 06 \text { september } 2021 \\
\text { Jam : } 09.00 \text { wib } \\
\text { 1. Menenangkan pasien } \\
\text { 2. Memahami keadaan pasien } \\
\text { 3. Mendiskusikan } \\
\text { penyebab,terjadinya proses } \\
\text { terjadi, tanda gejala,akibat } \\
\text { dari ansietas } \\
\text { 4. Latihan cara mengatasi } \\
\text { kecemasan : } \\
\text { - Teknik relaksasi nafas } \\
\text { dalam } \\
\text { - Distraksi dengan bercakap- } \\
\text { cakap hal positif } \\
\text { - Hipnotis 5 jari focus pada } \\
\text { hal yang positif } \\
\text { 5. Bantu Klien melakukan } \\
\text { nyylatihan sesuai dengan } \\
\text { jadwal kegiatan. }\end{array}$ & 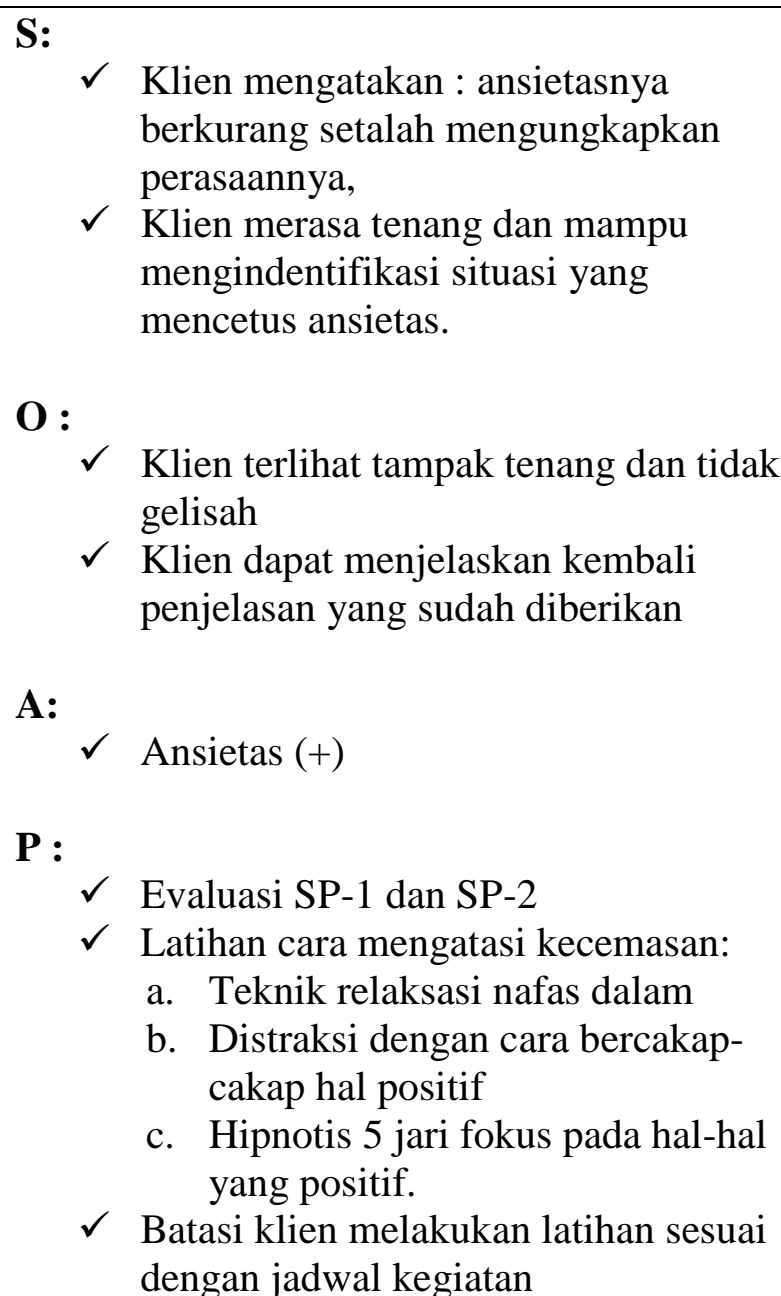 \\
\hline $\begin{array}{l}\text { Tanggal : } 07 \text { Setember } 2021 \\
\text { Jam : } 09.00 \text { Wib } \\
\text { 1. Latihan cara mengatasi } \\
\text { kecemasan : } \\
\text { a. Teknik relaksasi nafas } \\
\text { dalam } \\
\text { b. Distraksi bercakap-cakap } \\
\text { dengan hal yang positif. } \\
\text { c. Hipnotis } 5 \text { jari fokus pada } \\
\text { hal yang positif. } \\
\text { 2. Bantu klien melakukan latihan } \\
\text { sesuai dengan jadwal } \\
\text { kegiatan. }\end{array}$ & $\begin{array}{rll}\text { S: } & & \\
& \checkmark & \text { Klien mengatakan yang di rasakan } \\
& \text { lebih tenang dan tidak merasa cemas } \\
\checkmark & \text { Klien mampu mengidentifikasikan } \\
& \text { situasi yang mencetus Cemas } \\
\checkmark & \text { Klien mengatakan sudah melakukan } \\
& \text { teknik tarik nafas dalam } \\
\checkmark & \text { Klien mengatakan mampu melakukan } \\
& \text { teknik distraksi. } \\
\checkmark & \text { Klien mengatakan sudah mampu } \\
& \text { melakukan teknik hipnotis lima jari } \\
& \\
\mathbf{O}: & \\
\checkmark & \text { Klien terlihat tampak tenang dan tidak } \\
& \text { gelisah }\end{array}$ \\
\hline
\end{tabular}




\begin{tabular}{|r|r|r|r|}
\hline & $\checkmark$ & Klien mampu menjelaskan kembali \\
& & penjelasan yang sudah diberikan. \\
$\checkmark$ & Klien mampu menjelaskan teknik nafas \\
& dalam \\
$\checkmark$ & Klien mampu melakukan distraksi. \\
$\checkmark$ & Klien mampu melakukan hipnotis lima \\
& & jari. \\
& & \\
A: & $\checkmark$ & Ansietas (+) \\
& & \\
P : & & \\
$\checkmark$ & Bantu klien melakukan latihan sesuai \\
& & dengan jadwal kegiatan. \\
& $\checkmark$ & Terapi perilaku. \\
& $\checkmark$ & Terapi Kognitif. \\
& $\checkmark$ & Berikan pendidikan kesehatan. \\
& &
\end{tabular}




\section{BAB 4 \\ PEMBAHASAN}

Setelah penulis melaksanakan asuhan keperawatan kepada Tn.S dengan Kecemasan di Gg. Rukun No 78 A maka penulis akan membahas kesenjangan antara teoritis dengan tinjauan kasus. Pembahasan dimulai melalui tahapan proses keperawatan yaitu pengkajian, diagnosa keperawatan, perencanaan, pelaksanaan dan evaluasi.

\subsection{Pengkajian}

Selama pengkajian dilakukan pengumpulan data dari beberapa sumber, yaitu dari pasien dan tetangga sekitar. Maka penulis melakukan pendekatan kepada pasien melalui komunikasi teraupetik yang lebih terbuka membantu klien untuk memecahkan perasaannya dan juga melakukan observasi kepada pasien. Adapun upaya tersebut yaitu :

1. Melakukan pendekatan dan membina hubungan saling percaya diri pada klien agar klien lebih terbuka dan lebih percaya dengan menggunakan perasaan.

2. Mengadakan pengkajian klien dengan wawancara. Dalam pengkajian ini, penulis tidak menemukan kesenjangan karena ditemukan hal sama seperti: diteori: Kecemasan adalah keadaan emosi dan pengalaman subyektif individu, tanpa objek yang spesifik karena ketidaktahuan dan mendahului pengalamanya yang baru seperti penyakitnya saat ini

\subsection{Tahap perencanaan}

Perencanaan dalam proses keperawatan lebih dikenal dengan rencana asuhan keperawatan yang merupakan tahap selanjutnya setelah pangkajian dan penentuan diagnosa keperawatan. Pada tahap perencanaan penulis hanya menyusun rencana tindakan keperawatan sesuai dengan pohon masalah keperawatan yaitu: Kecemasan. Pada tahap ini antara tinjauan teoritis dan tinjaun kasus tidak ada kesenjangan sehingga penulis dapat melaksanakan tindakan seoptimal mungkin dan didukung dengan seringnya bimbingan dengan pembimbing.

Secara teoritis digunakan cara strategi pertemuan sesuai dengan diagnosa keperawatan yang muncul saat pengkajian. Adapun upaya yang dilakukan penulis yaitu :

1. Individu mengatakan ketidakpastian tentang fluktuasi tingkat energi dan bersikap pasif. 
2. Individu menunjukan sikap apatis terhadap perburukan fisik yang terjadi dengan mengabaikan kepatuhan pasien terhadap program pengobatan.

\subsection{Tahap Implementasi}

Pada tahap implementasi, penulis hanya mengatasi 1 masalah keperawatan yakni: diagnosa keperawatan Kecemasan merupakan keadaan emosi dan pengalaman subyektif induvidu,tanpa objek spesifik karena ketidaktahuan dan mendahului semua pengalaman yang di alami penyakit Hipertensi

\subsection{Tahap Evaluasi}

Pada tinjauan teoritis evaluasi yang diharapkan adalah :
a. Membina hubungan saling percaya
b. Mengenali dan mengekspresikan emosinya
c. Mampu mengenal ansietas
d. Mampu mengatasi ansietas melalui teknik releksasi
e. Mampu mengatasi ansietas dengan distraksi
f. Mampu mengatasi ansietas melalui hipnotis lima jari
g. Mampu mengatasi ansietas melalui kegiatan spritual 


\section{BAB 5 \\ PENUTUP}

\subsection{Kesimpulan}

Berdasarkan uraian pada pembahasan diatas, maka penulis dapat disimpulkan bahwa:

1. Pengkajian dilakukan secara langsung pada klien dan juga dengan menjadikan status klien sebagai sumber informasi yang dapat mendukung data-data pengkajian. Selama proses pengkajian, perawat mengunakan komunikasi terapeutik serta membina hubungan saling percaya antara perawat-klien. Pada kasus Jarang membersihkan Kecemasan: Hipertensi.

2. Diagnosa keperawatan yang utama pada klien dengan Kecemasan: Hipertensi

3. Perencanaan dan implementasi keperawatan disesuaikan dengan strategi pertemuan pada pasien.

4. Evaluasi keperawatan yang dilakukan menggunakan metode subyektif,obyektif,assessment dan planing.

\subsection{Saran}

1. Untuk institusi pendidikan

Penulis mengharapkan lebih meningkatkan pelayanan pendidikan yang lebih tinggi dan menghasilkan tenaga kesehatan yang profesional berwawasan global

2. Untuk keluarga

Penulis mengharapkan agar individu dan keluarga bisa mengerti tentang penyakit hipertensi, dan meningkatkan perilaku hidup sehat dengan tujuan meningkatkan kualitas hidup. 


\section{DAFTAR PUSTAKA}

1. Azzahra, F., Oktarlina, R. Z., \& Hutasoit, H. B. K. (2020). Farmakoterapi Gangguan Ansietas Dan Pengaruh Jenis Kelamin Terhadap Efikasi AntiansietaS. JIMKI: Jurnal Ilmiah Mahasiswa Kedokteran Indonesia, 8(1), 96-103.

2. Dina S (2021). Diam-Diam Mematikan, Cegah Asam Urat Dan Hipertensi. Yogyakarta: Penerbit Anak Hebat Indonesia.

3. Depkes RI. (2018). Balitbangkes Laporan Riset Kesehatan Dasar Provinsi Sumatera Utara Tahun 2018.

4. Hartanto, A. E., Hendrawati, G. W., \& Sugiyorini, E. (2021). Pengembangan Strategi Pelaksanaan Masyarakat Terhadap Penurunan Stigma Masyarakat Pada Pasien Gangguan Jiwa. Indonesian Journal for Health Sciences, 5(1), 63-68.

5. Hastuti, A. P., \& Kep, M. (2020). Hipertensi. Penerbit Lakeisha.

6. Hulu, E. K., \& Pardede, J. A. (2016). Dukungan Keluarga Dengan Tingkat Kecemasan Pasien Pre Operatif Di Rumah Sakit Sari Mutiara Medan. Jurnal Keperawatan, 2(1), 12.

7. Keliat, A, B, 2019. Asuhan Keperawatan JIwa. ed. M.App.Sc Prof. Dr. Budi Anna Keliat, S.Kp. Jakarta.

8. Kemenkes, RI. (2013). "Riset Kesehatan Dasar.": 88.

9. Kemenkes RI. (2018). Balitbangkes laporan Riset Kesehatan DasarProvinsi Sumatera Utara Tahun 2018.

10. Kemenkes RI. (2019). "Hipertensi Si Pembunuh Senyap.

11. Marbun, A., Pardede, J. A., \& Perkasa, S. I. (2019). Efektivitas Terapi Hipnotis Lima Jari terhadap Kecemasan Ibu Pre Partum di Klinik Chelsea Husada Tanjung Beringin Kabupaten Serdang Bedagai. Jurnal Keperawatan Priority, 2(2), 92-99. https://doi.org/10.34012/jukep.v2i2.568

12. Marta, D (2013). "Asuhan Keperawatan Ansietas Pada Ibu S Yang Mengalami Hipertensi Di Ruang Rawat Antasena Rumah Sakit Dr. H. Marzoeki Mahdi Bogor."

13. Prasetyanigrum (2014). "Hipertensi Bukan Untuk Ditakuti." In FMedia, Jakarta Selatan: FMedia.

14. Pardede, J. A. (2020). Standar Asuhan Keperawatan Jiwa Dengan Masalah Kecemasan.

15. Pardede, J. A., Simanjuntak, G. V., \& Laia, R. (2020). The Symptoms of Risk of Violence Behavior Decline after Given Prgressive Muscle Relaxation Therapy on Schizophrenia Patients. Jurnal Ilmu Keperawatan Jiwa, 3(2), 91-100.

16. Pardede, J. A., Sitepu, S. F. A., \& Saragih, M. (2018). Pengaruh Teknik Relaksasi Nafas Dalam dengan Terapi Hipnotis Lima Jari Terhadap Kecemasan Pre Operatif. Jurnal Kesehatan Jiwa, 1(10).

17. Pardede, J. A., Keliat, B. A., Damanik, R. K., \& Gulo, A. R. B. (2020). Optimalization of Coping Nurses to Overcoming Anxiety in the Pandemic of Covid-19 in Era New Normal. Jurnal Peduli Masyarakat, 2(3), 105-112.

18. Pardede, J. A., Sinaga, T. R., \& Sinuhaji, N. (2021). Dukungan Keluarga Dengan Tingkat Stres Narapidana Di Lembaga Pemasyarakatan. Window of Health: Jurnal Kesehatan, 98-108.

19. Rahmawati, Lisa, dan Ningsih, M (2016). Faktor-Faktor Yang Berhubungan Dengan Kejadian Asfiksia Pada Bayi Baru Lahir Di Ruang Medical Record RSUD Pariaman. Jurnal Ilmiah Kebidanan 7(1): 29-40.

20. Stuart, Gail W., Budi Anna Keliat, and Jesika Pasaribu. (2016). Keperawatan Kesehatan Jiwa. Indonesia: Elsever.

21. Prasetyanigrum, Y, I, (2014). "Hipertensi Bukan Untuk Ditakuti.” In FMedia, Jakarta 